\title{
Service orientation: changing in Tunisian industrial firms
}

\section{Afef Ben Youssef Zghidi*}

Higher Institute of Technological Studies of Communications of Tunis, Technopole el Gazala, Route de Raoued - km 3.5, 2083, Ariana, Tunisia

Email: afefbenyoussef@yahoo.fr

${ }^{*}$ Corresponding author

\section{Imed Zaiem}

Faculty of Economic Sciences and Management of Nabeul, Campus Universitaire,

Mrezga, Route Hammamet, 8000 Nabeul, Tunisia

Email: imed.zaiem@fsegt.rnu.tn

\begin{abstract}
This paper focuses on the development of services in industrial firms. Specifically, the main objective is to identify the antecedents of service orientation. It first presents the existing literature to understand how industrial firms adopt and develop service in their business strategies. Second, it shows the results of a field study implemented in Tunisian industrial firms. The study revealed that the managerial motivation, the firm and environment characteristics have potential effects on service orientation.
\end{abstract}

Keywords: service orientation; industrial firms; managerial motivation; firm characteristics; environment characteristics.

Reference to this paper should be made as follows: Zghidi, A.B.Y. and Zaiem, I. (2015) 'Service orientation: changing in Tunisian industrial firms', Int. J. Strategic Change Management, Vol. 6, No. 1, pp.1-20.

Biographical notes: Afef Ben Youssef Zghidi has obtained a Doctorate in Marketing from the Faculty of Economic Sciences and Management of Tunis (TUNISIA). She is a teacher-researcher at the Higher Institute of Technological Studies of Communications of Tunis. Her research interests are in the areas of industrial marketing, marketing management and international marketing.

Imed Zaiem is a Professor at the Faculty of Economic Sciences and Management of Nabeul. He holds a Doctorate in Marketing from the Tunis Management and Economics Faculty, Tunis El Manar University. His research interests are in the areas of marketing management research, marketing data analysis and consumer behaviour. 


\section{Introduction}

During the last three decades, we continuously noticed a predominance of services in all world economies (Lovelock et al., 2008). In fact, facing the new market trends, firms are more and more numerous in adjusting their offers in the profit of services (Gebauer and Fleisch, 2007; Vargo and Lusch, 2008). Consequently, all the organisations in all the sectors, in both developed and developing countries, are witnessing real transformations.

Previously, several industrial firms thought that only innovation, technological progress and/or price decline will allow them to acquire a competitive advantage. However, today, current market realities indicate that service offer is more and more imperative to industrial firms (Furrer, 1997, 1998; Gebauer et al., 2005; Mathieu, 2001a, 2001b) as it has become a significant factor of growth and competitiveness (Malleret, 2006; Tzokas et al., 2000). Today, offering a basic product is not enough; there is a need to suggest extra services that increase the value of the offer. In addition, it is thanks to service valorisation that certain firms have largely increased their annual revenues. Particularly in the industrial context, the development of services is constantly taking ground and even exceeds the growth of services in other sectors (Balgin and Malleret, 2004).

Therefore, industrial firms show a permanent mutation. Services have certainly and greatly changed the industrial activity (Mathieu, 2001b). In fact, services have the potential to change the industrial activity's culture and fundamental characteristics (Mathieu, 2001b) and can even intervene in all the operations of the production process (Wagner and La Garce, 1981; Xu et al., 2011). More specifically, the classic value chain (production-product sales) lost some of its efficiency, especially that the benefits linked to product sales are decreasing in some markets (Almeida and Miguel, 2009; Salonen, 2011). It is therefore questionable to admit that the product remains the only important element of the offer. Firms move from a purely 'traditional' industrial and technical culture (in which the product formed the centre of the industrial offer) to a new culture based on an orientation towards offering services (Tan et al., 2010). This progressive passage is considered by some scholars as a global phenomenon called 'servitisation' of the industry (Ren and Gregory, 2007; Slepniov et al., 2010; Vandermerwe and Rada, 1988). Today and in this respect, all the industrialists give propositions of combined product and service offers on the market to create value and make the difference compared to their competitors (Vandermerwe and Rada, 1988).

Drawn by the benefits associated with services, several firms attempt to implement a strategy oriented towards service offer to guarantee customer loyalty (Driver and Johnston, 2001). In fact, this service orientation constitutes a new philosophy that mobilises all the firm's efforts. This is only a concrete manifestation of a will to commit to a long-term relationship with the clients (Mathieu, 2004) and to help them realise the expected benefits from goods' use (Kotler, 1997).

Facing the rising interest shown by firms, the development of service offer within industrial firms has always been a subject of interest in academic research. In this respect, we notice that this subject constantly draws the authors to study the fields of antecedents and consequences of service orientation. For instance, to scholars such as Furrer (1997) and Solnet and Kandampully (2006), market orientation is considered as an antecedent to service orientation. Particularly in the industrial field, to be oriented towards its market allows the firm to improve its performance (Furrer, 1997). To achieve this, it has to create 
a value that is superior compared to the competitors by suggesting a performing product/ service system. However, the growing number of studies on service orientation and the mixed findings have greatly complicated the efforts among searchers and practitioners, especially to find the real antecedents of this construct. In this scope, we aim to review principal works that highlighted the importance service orientation within the industrial context.

Furthermore, previous studies were generally concerned in developed countries. For this reason, the empirical study of this research was realised in Tunisia, an emerging country in transition phase. We have achieved a field study implemented in Tunisian industrial firms.

\section{Conceptual framework}

\subsection{Service orientation of industrial firms}

The current industrial context is characterised by a tireless competition. The significance of the price and the product itself has greatly decreased. So, facing these new parameters, the firm is constrained to reorient its strategy to move from product orientation to service orientation (Tan et al., 2010). In fact, industrial firms usually tend to favour either a product orientation or a cost orientation. It is the 'traditional' culture that orients the industrial mind towards the product and technological innovation and/or gives priority to maintaining low costs. This reflects a weak strategic vision in terms of service while the fact of not integrating the services since the conception of the product engenders poor quality coordination between the product and the service in addition to significant costs (Furrer, 1997).

\subsubsection{The dilemma: services in the industry}

The product and the services in the industrial offer have now become tightly linked. Rock and Ledoux (2006) state that the concept of the product usually encompasses the service. Philippe and Léo (1996) find that products are made of both tangible and intangible attributes which means that the frontiers between products and services weaken when the development of services increases a product offer. Consequently, it has become difficult to manage and develop this complex offer system that is both combining product and service. Owing to the latter's various specificities, firms are confronted to a certain number of dilemmas that need to be solved. Thus, according to Furrer (1997), services are more difficult to define and evaluate in a precise way than products are. For this reason, the management of a 'product/services' system is even more complex than the management of a product or a service taken individually. Thus, traditional marketing practices can no more be transferable in this respect as we speak of a new marketing system. All the challenge lies in efficiently managing this change of activity. It is necessary to look for the balance between the product elements and the service elements to form the most competitive offer on the market. However, it is to note that it would usually be wise to favour an element in terms of the competitive objectives that are followed (Eiglier and Langeard, 1987). This shows the particularity of marketing the services in industrial firms, particularly if the offered services are diverse. 


\subsubsection{Diversity of the services offered in industry}

The services are heterogeneous. Almeida and Miguel (2009) state that several terms were used in this respect among which many from Anglophone works. One can cite the following terms: industrial service, product-linked services, customer service, after-sale service and customer support. This heterogeneous aspect stems on the one hand from the diversity of customer needs and expectations, and on the other, from the different objectives followed by the firm (Furrer, 1997). For this reason, industrial firms generally propose different types of periodical services (Almeida and Miguel, 2009; Mathieu, 2001a, 2001b). This implies that the role of services changes with the time. Concretely, this service dynamics perceived as a complex transitional process forms an organisational learning (Lee, 2004), describing the role and place that various services can take within the same firm (Malleret, 2005). We here speak of a set of steps moving the firm from the status of a firm offering an industrial product to a new status of a service firm (Olivia and Kallenberg, 2003; Malleret, 2005). However, there are several elements that hamper the implementation of a service strategy in an industrial firm. It is then necessary to implement a service culture in the firm (Pinet and Coupet, 2009). In this case, services are integrated in the managerial and strategic decisions. In other words, highly significant decisions coming from top management have to be taken to meet the objectives; hence the necessity to have a global approach that is manifested through a service strategy named by the scholars "firms" service orientation"; a behavioural alternative of market orientation in the industrial firm.

\subsubsection{Service orientation: definitions}

Service orientation - a recent concept - was among the most studied topics in the industrial marketing and management fields. The advantages linked to the service offer formed the most significant topic to which scholars gave much importance. But in spite of this mass of research, the strategic perspective of service orientation did not receive the same interest (Homburg et al., 2002). Lytle et al. (1998) and Homburg et al. (2002) consider this concept to be a new aspect of the firms' marketing dimension; but it is to note that this concept has differently been treated in the literature. The first ideas on service orientation came from the works of Hogan et al. (1984) according to whom service orientation designates " $a$ set of attitudes and behaviours affecting the quality of interaction between an organisation's employees and its customers". To these scholars, service orientation can be defined from an individual level. In this case, service orientation reflects individual predispositions and a courteous and friendly disposition when providing the service. On the other hand, the authors have developed a measuring scale highlighting the personality variable. This scale was later validated by Cran (1994).

Contrary to the previous perspective, the organisational perspective was much more examined in the literature. For instance, Lytle et al. (1998) stated that service orientation reflects the organisational climate, creates, cultivates and rewards service practices and behaviours which are accepted as satisfying customer expectations. In this perspective, a scale named 'SERVOR' was developed by Lytle et al. (1998). The scale indicated the extent to which the firm adapted its managerial structure for a better service offer. However, this definition with a 'purely organisational' vision does only takes into consideration the firm's internal factors. External environment is a little discarded. 
Though it is important to take into consideration internal factors, it is also interesting to consider the service offer as a set of strategic decisions that depend on the external environment of the firm. In fact, Solnet and Kandampully (2005) think that service orientation must be viewed as a strategic initiative. But at the same time, it constitutes an evolutionary concept that varies according to customer needs. Hence, a strategic rather than an organisational vision is necessary as it implies taking into consideration the external parameters of the firm. Within this same line of thought, Bowen et al. (1989) think that the firm's service orientation allows for the improvement of its customer satisfaction. In fact, it constitutes the best competitive marketing strategy; yet among the most interesting works to present is that of Homburg et al. (2002).

These researchers showed that service orientation is the result of three factors developed by Homburg et al. (2002):

- "The number of services offered,

- The number of customers these services are offered to,

- The level of emphasis with which these services are actively offered".

This definition is of particular interest. First, Homburg et al (2002) rigorously studied these three dimensions of service orientation. Besides, this definition reflects the perception of the managers towards the importance of service in their activity (Antioco et al., 2008). Last, it describes the firm's practice in terms of service in its totality (number of services, type of client, and type of services and reactivity in offering services). To our knowledge, this was the most retained definition in the course of these last years.

\subsection{The relationship between market orientation and service orientation}

In most of the previous research, it was demonstrated that service orientation of industrialists implies the commitment of all the organisations to be able to satisfy the customers' expectations (Furrer, 1997; Gebauer and Fleisch, 2007; Tzokas et al., 2000). Some authors even found that the relationship between market orientation and performance is stronger in industrial firms than in service firms (Kirca et al., 2005). We therefore speak of a new service culture that is integrated within the industrial firm. The latter has to be customer oriented and in general market oriented to better understand its customers' needs. Certainly, service orientation and market orientation have become two concepts that are tightly linked (Rock and Ledoux, 2006). In other words, service orientation is part of a firm's global vision, i.e., of a market orientation. In another context, Alrubaiee (2013) proved that market orientation has a positive effect on the development of new services in service firms. On the one hand, the author proved the positive relationship between market orientation and performance. On the other, the results confirmed that the new service offer is a powerful variable in this relationship (see Figure 1).

If we examine the works realised in the industrial sectors, the literature shows that one has to take into consideration the significance of the engendered cultural and organisational mutations within an industrial firm to offer services (Philippe and Leo, 1996). Neglecting the service in the proposed offer proves that the firm is not oriented towards its market. However, it is not incorrect to say that to satisfy customer needs, the firm can also highlight several other criteria such as the cost of technology (Jaworski and 
Kohli, 1996). All depends on the firm's environment. For example, Day (1994) proved the necessity to include goods and services as inseparable elements in the fields characterised by high technological intensity. However, this specifically depends on customers' expectations. Actually, customer needs are highly divergent. As we already noticed, customers do not give the same importance to the product's characteristics: be it innovation, technology or service. Certain factors can be the cause of this divergence: competitive offer, type of the product or even the same customer category (Furrer, 1997).

Figure 1 Alrubaiee's (2013) conceptual model

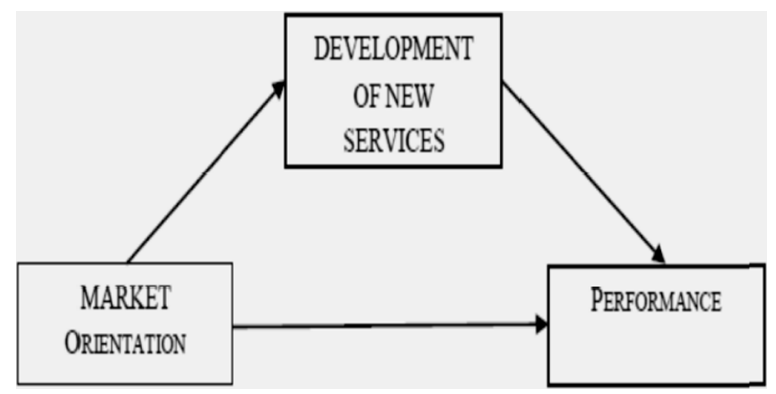

Rock and Ledoux (2006) think that the firm has to rethink its management philosophy and apply "an approach that consists in orienting the firm towards the satisfaction of customer needs notably by the implementation of procedures that are centred on the service offered to the client in terms of products or services". To them, the terms 'customer approach' and 'customer service' are synonymous. In fact, an efficient customer service is integrated in a more global vision of the firm, i.e., in the customer approach. Similarly, Gebauer et al. (2011) affirmed that if the industrial firm wants to be market oriented, it has to offer more services. The aim is to respond in the best way to the current and future needs of the clients by creating value from services (Malleret, 2006). Within this scope, Tournois and Montebello (2001) proved that it has become imperative to offer a powerful product/complementary services system. These services should be superior to those provided by the competitors. To the above-mentioned scholars "the creation of value is the capacity of the firm to propose a perceived value, that is superior than the competition, to the customer taking into consideration the offers to which he/she has access" (Tournois and Montebello, 2001). This system of value creation constitutes an element that is integrated in the perspective of market orientation "a system that links the variables affected by the managerial decisions to behavioral responses of the competitors, customers and markets" (Tournois and Montebello, 2001). Thus, the creation of value highlights the firm's resources, especially intangible ones.

Recently, a new research paradigm has brought a new outlook to the marketing field. We speak of a new logic called 'Service-dominant logic' (Vargo and Lusch, 2008) or 'Service as business logic' (Grönroos and Ravald, 2011). The founding works of Vargo and Lusch (2004) confirm the preponderant place of the service in the relationship firm/client. They propose that the value of property (whether durable or consumable) be defined by its usage and more importantly by the service it offers. The service constitutes thus the basis of exchanges having as an implication a creation of a superior value (Grönroos and Ravald, 2011). To be market oriented inevitably requires a new logic that turns around service. However, the principle is to put the service at the centre of all 
strategic reflections of the firm. In fact, the current context, characterised by the tertiarisation of the economy, makes the creation of value via the complementary service a key success element of a market-oriented strategy and a means to be differentiated from competitors particularly for industrial firms (Malleret, 2006).

Philippe and Leo (1996) reinforce Reffait's stand (1993) according to which 'the passage from product orientation to service orientation presupposes the passage from a production orientation to a market orientation'. Equally, the research of Furrer (1997) highlighted the service offer as a vital element of the behavioural aspect of market orientation. He suggests the following normative model (see Figure 2).

Figure 2 Furrer's (1997) normative model

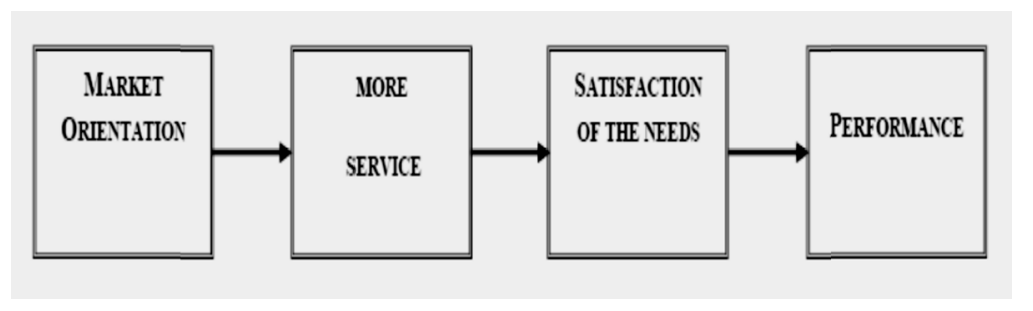

Following this normative model, market orientation constitutes an antecedent to service offer. The idea postulates that when an industrial firm aims to improve its performance, it has to be market oriented to satisfy the current and future customer expectations and consequently create value. Creating a value that is superior to that of the competitors rests on a performing product/service system. In fact, market orientation, founded on customer satisfaction (Gotteland et al., 2007), could incite the industrialists to propose the best combined offer of 'product-service' on the market. Services become more and more integrated in the global offer and cannot, therefore, be limited for instance to simple aftersale services. However, we deduce that firms usually adopt different strategic orientations at the same time which makes it difficult to distinguish the influence of one over the others on the service offer. Therefore, the question is whether independently from industrial firm orientation will the importance given to services be the same? In fact, if the firm is rather interested in offering different competitor products while looking for a constant technological innovation or if it simply aims at maintaining low costs will the service offer remain vital?

\subsection{Antecedents of service orientation: a literature review}

Whether in marketing or management, many searches have tried to find the antecedents of the service orientation of a firm. In this context, the literature review allows us to distinguish between internal and external antecedents.

\subsubsection{Internal antecedents}

To our knowledge, some internal antecedents were identified in previous studies.

- Firm's orientation

Mosadeghrad and Ansarian (2014) found that among the factors that inhibit the successfully implantation of organisational change was the insufficient customer focus. 
On the basis of different definitions of market orientation, the customer must be at the centre of all business activity. In some research, market orientation is considered a structural history bearing on the provision of service. According to Brady and Cronin (2001), the majority of studies on the service offering emphasised the importance of market orientation. Sometimes the market orientation refers to the orientation service term (Cran, 1994).Moreover, market orientation may facilitate the implementation of a strategy based on service (Solnet and Kandampully, 2005). In fact, the transition to services may affect the entire culture of the industrial enterprise (Mathieu, 2001a, 2001b; Olivia and Kallenberg, 2003). Therefore, an efficient service orientation should be integrated into the overall strategic level of the firm. For Furrer (1997), even if it is a manufacturing firm, the whole firm must give a picture of the service. It is replacing a product oriented with a focus on maximum market satisfaction.

- Firm's managers

According to Ordonez De Pablos (2004), the intellectual capital is the essential factor for the performance and the success of organisations. In the current turbulent economy and especially for high-tech industries, it is very important to improve intellectual capital to stay competitive. In fact, this factor can help organisations to create value and can get better innovation and creativities in organisations. As suggested by Khalique et al. (2013), now in a knowledge-based economy, intangible assets are considered as the most important resources for the success of organisations. In fact, intellectual capital is mainly based on the soft assets of the organisations that contribute to boost the performance of the organisation. Managers can have a vital role to develop intellectual capital to make a change in a firm.

The attitude and commitment of the 'Top management' strategy are to generally influence the behaviour of employees throughout the organisation (Millson and Wilemon, 2002; Venkatesh and Davis, 2000). In fact, the effective implementation and the success of any strategy require managerial motivation and supporting organisational arrangements (Asikhia, 2010; Gebauer et al., 2005). Specially in the industrial context, the expansion of service activities is primarily owing to the importance given by the managers of the firm (Gebauer et al., 2005).

Extending the service business seems to be a change in an industrial firm. Therefore, a high degree of managerial motivation reflects the desire of a firm to adapt to change to meet the needs of its customers in a more efficient manner than its competitors.

To understand the antecedents of service offering in industrial firms, Gebauer and Fleisch (2007) and Antioco et al. (2008) are based on the behavioural perspective and motivation theory of Vroom (1964). According to them, if the direction of the firm attaches importance to the expansion of services in the supply of the firm and whether it expects a gradual improvement of its objectives, it will be motivated to invest in activities service in its global offer. Service orientation is industrially influenced by the motivation of managers. Assuming imperative of service in the industry, Tzokas et al. (2000) developed a scale to measure the commitment of senior management to the service. For them, the commitment of management supports the success of the development strategy of offering customer service. But in addition to the commitment to service, the authors suggested the need to consider other factors related to firm executives as personality, beliefs and values (Tzokas et al., 2000). 
- Firm's activity

In addition to its general orientation, the type of products offered on the market and the types of clients that the firm addresses can be two elements that may reflect the activity of a firm.

For some authors, customers currently look for a solution, a combined offering product and services. The only product is no longer seen as a central element of the offer of an industrial firm. Gradually, it became a determinant of service orientation (Lay et al., 2010).

In this context, Furrer (1997) showed that the ability to offer services around the product depends on the product itself. It is scalable, innovative or poorly differentiated, the product directly generates demand growth complementary services (Furrer, 1997).

Lay et al. (2010) were able to show that the extent of the service offering in the industrial firms depends on the type of product offered. In other words, it is the nature of the products that drive customers to demand more services from their suppliers. In general, the complexity of the product is the main feature that engages the industrial enterprise to provide additional services (Olivia and Kallenberg, 2003).

According to Philippe and Leo (1996), the firms which offer more complex products are those that are naturally concerned by the expansion of the service offer. For example, we note that equipment products, characterised by a complex technological level, have been the most used in previous empirical studies (Mathieu, 2001b; Olivia and Kallenberg, 2003).

Also, the nature of clients served is also considered an important determinant of service orientation for some authors.

On the basis of the definition of Homburg et al. (2002), the customer is the centre of the service strategy. Indeed, with hopes for a personalised offer, the customer demands more and more services (Balgin and Malleret, 2004). This product differentiation by service requires taking into account the characteristics of the customers to who services are provided. It is generally recognised that customer needs are different. Whether companies or individuals, the scope of services in industrial and business depends on customer type (Furrer, 1997).

In addition and in conjunction with the firm's offer, another result seems interesting. Indeed, some authors such as Philippe and Leo (1996) found that firms belonging to different industrial sectors follow a tertiary supply differently.

\section{- Organisational factors}

Pettus et al. (2009) have showed that strategic flexibility was required in the firm growth. In addition, they have suggested that the firm's capabilities to respond to changing conditions in the external environment depend on the organisational learning. These two factors can play an important role in enacting change in firms.

Several authors have shown that organisational parameters for an industrial firm have a great importance in the implementation of a service strategy (Antioco et al., 2008; Vandenbosch and Weinberg, 1994). Indeed, these are the characteristics of the service that require more effective management. The intangible aspect of service combined with the tangible nature of the product returns to the problem of resource management and coordination between different departments of the firm. For Denis et al. (2000), the top management's commitment to the strategy is necessary but not sufficient. Greater 
efficiency in management is necessary for a firm moves towards its market. In this sense, a program involving coordination between different departments, communication and dissemination of information on customer needs will foster a climate to engage the entire firm to provide quality services. In this regard and according to Mosadeghrad and Ansarian (2014), many organisations have found it difficult to implement organisational change successfully. The success of the implementation of the change program and its impact depends on many factors. 'Poor communication' was considered as the important one of these factors.

On the basis of a qualitative study of a large industrial company, Gadolin (2014) studied the effect of internal communication as an important factor in major change management projects. Indeed, internal communication can help establish a process of change as managers and all employees will have a better perception of it.

In her research on the subject of the importance of diffusion of innovation, Banks (2006) suggests that the understanding the communication channel can help human resource management representatives manage change.

Gebauer et al. (2005) also agree. They add that some aspects in the business must exist to implement a strategy-oriented service in an industrial firm. Mainly, it must:

- $\quad$ establish a clear strategy to develop service orientation

- recognise that service as a source of value creation for the customer

- $\quad$ initiate a program of relationship marketing

- clearly define the service strategy

- $\quad$ establish a separate service unit

- create a service culture within the firm.

\subsubsection{External antecedents}

According to Solnet and Kandampully (2005) and Gebauer (2008), the implementation of a strategy focused on providing service must take into account external factors including the firm, demand and competition. Some other authors add the technological environment (Day, 1994) and market structure (Furrer, 1997; Gebauer, 2008). In addition, but in another context, Homburg et al. (2002) studied the referral service distributors. They highlighted other external factors such as competitive intensity.

\section{- Competitive intensity}

For Solnet and Kandampully (2005), knowledge of supply competition allows a firm to evaluate its market position and track market trends. Referring to research on market orientation, competitive intensity reflects the manoeuvres used by competitors to gain a competitive advantage (Jaworski and Kohli, 1993). This intensity also refers to existing competitors in a sector (Homburg et al., 2002).

In general, the competitive intensity in a market maximises the pressure from customers. Therefore, the firm will be obliged to match the offer of the competition, especially if it provides complementary services (Balgin and Malleret, 2004). More the competitive intensity, the higher the firm is oriented towards service offering (Homburg et al., 2002). 


\section{- Technological environment}

As we have already discussed in the previous paragraph, the type of product is a determinant of service orientation. It is precisely the complexity of the product which implies a growing demand for service. This complexity often refers to the technological aspect of the industry.

This technological factor was also presented by Narver and Slater (1990) as a determinant of market orientation of a firm. But in connection with our research topic, Day (1994) and Kumar and Markeset (2007) assume that the supply of services is strongly required in a highly technological field. In this sense, the technological aspect of a sector may be considered as a determinant of service orientation.

\section{- $\quad$ Market structure}

Narver and Slater (1990) studied the growth of the market as a determinant of market orientation of a firm. In the same vein, Furrer (1997) and Gebauer (2008) found that the appearance of the market growth will influence the supply of service in an industrial firm.

\section{Research method}

\subsection{Qualitative research}

To identify the antecedents of service-oriented industrial companies, we decided to make a qualitative study. For this, we have made individual qualitative interviews. This type of interview is often the most used to gather information especially in the field of industrial firms (Pellemans, 1999). Indeed, it is very difficult to organise group discussions involving competitors in industry. The method used is a semi-structured interview.

Furthermore, and since we start with a structured interview guide and since it is difficult to record the information gathered in the interviews, the method of analysis of the data used is the analysis summary. Although simple, this method is most commonly used in industry (Pellemans, 1999). The analysis contained and thematic requires a complete recording of the interviews.

To collect data, we asked questions that revolve mainly around the following themes:

- the offered service

- the antecedents of service orientation

- the pricing strategy of services.

\subsection{Data collection}

We are interested in the offer of services in industrial firms. Therefore, the field of investigation for this study must be consistent with our initial goal.

However, it should be noted that the majority of previous research on service orientation of industrial enterprises were conducted in developed countries. For this reason, the empirical study of this research was conducted in Tunisia: an emerging country in transition. 
With a confirmed expertise and skills valued, Tunisia has become a place of choice for many local and foreign investors. Particularly in the industrial sector, the country has a remarkable development in recent years (API, 2012).

Tunisian industrial sector is very diverse, but the pillar sectors of Tunisian industry are three (API, 2012). These three sectors account for $76 \%$ of industrial sector. In addition, these sectors contribute to $87 \%$ of Tunisian exports. We distinguish the mechanic and electronic industry, the clothing and textile industry and food industry.

Mainly, these three sectors hold a common point. Indeed, one of the key success factors of the sectors mentioned above is that they all tried to adapt their operation and their strategies to cope with changes in consumer behaviour and new competitive forms. However, they have different characteristics. These differences in mode of operation will allow us to compare to highlight the behaviour and marketing practices of industrial enterprises in terms of service in these sectors. In our qualitative research, companies interviewed belong to these three industrial sectors.

\section{Results}

On the basis of the principle of responses' saturation, five semi-structured interviews were undertaken in five different industrial companies. Indeed, and based on GauthySinéchal and Vandercammen (2005), the sample size is less important in the qualitative study in the quantitative study. Then one of the conditions needed to make a qualitative study is to conduct interviews until arriving when the information sought will become redundant.

The study shows several interesting results.

We have summarised the results in the following table (see Table1).

From the previous table we mainly distinguish the antecedents of service orientation in industrial firms. These factors can be classified into three groups:

- $\quad$ antecedents relating to managers: managerial motivation to provide services

- antecedents relating to firm characteristics: general orientation, product type, targeted clients

- $\quad$ antecedents relating to environment characteristics: competitive intensity, industry technology intensity, market growth.

Some works supposed that industrial businesses that decide to offer services are motivated to dedicate some resources to the service activity (Gebauer and Fleisch, 2007; Gebauer et al., 2005). The more the managers perceive a positive value and benefit of the deployed effort and obtained results in service delivery, the more they tend to be service oriented. Some authors equally think that market orientation is an antecedent of the manufacturers' service orientation (Furrer, 1997, 1998; Reffait, 1993; Philippe and Leo, 1996). Therefore, we suppose that service orientation in the industrial business varies according to its principal strategic orientation. We identify three strategic groups in industry reflecting three different behaviours according to Furrer (1997):

- Customer orientation: The principal aim of the firm is to achieve maximum customer satisfaction. We thus suppose that this strategy favours the increase of the offer and service customisation. 
- Product orientation: The main objective is technological innovation. We then suppose that the firm focuses on technical services.

- Low cost orientation: The principal objective is to maintain very low costs. We thus suppose that the firm tries to offer standard services only and dedicates few resources to the service activity.

From another perspective, service orientation of industrial firms stipulates a relationship between services and sold products (Balgin and Malleret, 2004; Furrer, 1998). It is therefore necessary to check whether certain products need more services (or specific ones). In this same scope, equipment-related products are more likely to generate additional services (such as maintenance) than component-related products (Balgin and Malleret, 2004). Consequently, service orientation can vary according to the type of the sold product.

Table 1 Results of qualitative research

\begin{tabular}{ll}
\hline Themes & Responses \\
\hline Theme 1: & \\
(a) Motivation to provide services & Retention of clients \\
& Acquisation of clients \\
& Increase profitability \\
& Generate additional revenue through services \\
& Maintain a certain price level, and argue if the \\
& price is expensive \\
& Create a good image \\
& Comfort the client for its decision \\
& Advice to clients \\
& Regular visits to clients and prospects \\
& Speed of response to client requests \\
& Ease of access to staff \\
& Repair and preventive maintenance \\
& Product technical support \\
& Timely delivery \\
& Discounts, competitive credit \\
Caring support personnel \\
\hline Theme 3: Pricing strategy of services & Competitive intensity \\
& Type of products \\
& Clients \\
& Market orientation \\
& Industry Technology intensity \\
& Market growth \\
\hline Theme 2: Antecedents of service orientation & in the product price \\
& Personalised services are charged \\
& \\
& \\
& \\
& \\
& \\
&
\end{tabular}


It is important for managers to know whether services are of the same importance to individuals as to private or public firms (Furrer, 1997). In fact, industrial business service delivery has to be dedicated and adapted to its customers' needs to better satisfy them and minimise costs. On this point, results discussed in the literature are divergent. Tzokas et al. (2000) did not find a significant link between the customers' basic nature and the firm's behaviour in terms of service. Besides, Balgin and Malleret (2004) have not detected a significant difference between firms targeting individual customers and those targeting firms. However, others proved that service delivery varies according to the type of customers served (Furrer, 1998) and their characteristics (Homburg et al., 2002). Therefore service orientation varies according to the type of customers targeted.

For external variables, Philippe and Leo (1996) affirmed that the more the sectors of offered products are competitive, the more the firms resort to offer tertiarisation to become distinguished from other firms. However, Homburg et al. (2002) showed that the firm's service orientation is not linked to the sector's intense competitiveness. In addition, the technological extent of the sector leads the firm to offer more services (Furrer, 1998; Kumar and Markeset, 2007). Consequently, service orientation is more intense when the sector is highly competitive. Service orientation is more intense when the sector is highly technological.

Furrer (1997) identified a significant negative relationship between the importance of offered services and market growth. Service orientation is less intense when the market is significantly growing.

The main objective of our qualitative research is to determine the antecedents of service orientation. Besides this main objective, we determine the specific dimensions of service which the industrial firm considers to be important to provide service to their clients, such as maintenance, timely delivery, advice to clients and so on.

In addition, our study show the managers' evaluation of motivational reasons attributed to a firm commitment to service such as improved competitiveness, retention of clients, increased profitability and so on.

Finally, we found that in terms of pricing strategy of services, industrial firms include services cost in the product price but personalised services are charged separately.

\section{Conclusion and managerial implications}

Major changes hit the competition modes and the economy in general. Besides, the consequences of these changes are numerous on the activity of each firm. Within this scope, service orientation within industrial firms constitutes a major change and one of the most emerging new phenomena (Baines et al, 2009). For this reason, this theme is the most privileged in recent research on marketing and industrial management.

Starting from these conclusions, we tried through the present paper to review the literature written on the concept of service orientation.

In the research elaborated on the service orientation of industrial firms, the majority was inspired from the works on market orientation. In this scope, the authors agree in thinking that the industrial firm has to further favour market orientation. In addition, this orientation has to be proactive to anticipate the future changes of the market (Ketchen et al., 2007).

In this regard, Furrer (1997) showed that if the industrial firm is market oriented, its primary objective is the satisfaction of its customers. For this reason, it will necessarily 
increase the volume of its offered services which implies that industrialists who are looking to increasing their performance have to suggest the best combined offer of 'products-services' on the market. However, from the extent to which the managers can set innovation or cost reduction as a primary objective, the volume of offered services can decrease. The same is argued by Philippe and Leo (1996), the industrial firm looking to offer more services requires first of all a profound change from a production orientation to a market orientation.

Thus, it is to note that a vision that is centred on the product or the cost, reflecting that a classical industrial culture does not ensure the implementation of a long-term reliable service system. However, service orientation, thus part and parcel of the strategic level, would increase the value of the product. In this regard, market orientation, founded on customer satisfaction (Gotteland et al., 2007), could incite the industrialists to propose the best combined product-service offer on the market. In brief, market orientation is only an antecedent to the service orientation of the industrialists.

The firm that proposes a packaged offer of products and services on the market enters in a dynamics generally accompanied by a change in attitudes and behaviours. For this reason, the service offers in the industrial sector differ from one firm to another, yet equally from one period to another, and this can be for one same firm. Therefore, the service offer changes with time, passing from the level of operational decisions to that of managerial decisions, which thus proves that it is not enough to integrate the services in marketing objectives. On the contrary, services have to be taken into consideration on the strategic level of the firm. Their implementation imperatively goes through all the levels in the firm. In this case, we speak of the service orientation of industrial firms as a behavioural alternative to market orientation.

Our theoretical analysis highlighted the eventual importance of service orientation in industrial firms. Furthermore, we concluded that a number of researchers have tried to determine the antecedents of service orientation. However, there is a mixed finding in previous studies and there is luck of studies performed in emerging countries. That is why a qualitative research was undertaken with Tunisian industrial firm to identify mainly the real antecedents of service orientation.

By the way, we find that the antecedents of service orientation can be classified into three groups:

- antecedents relating to managers: managerial motivation to offer services

- antecedents relating to the firm characteristics: general orientation, product type, targeted clients

- antecedents relating to the environment characteristics: competitive intensity, industry technology intensity, market growth.

At the managerial level, our findings provide some recommendations to industrial firms. Above all, and even if services' input is not considered to be systematic in some studies, service orientation of manufacturers remains imperative in all the sectors to which they belong. We, therefore, think that a combined industrial offer of products and services can increase customer satisfaction. Marketing managers have to commit to look for new opportunities by giving importance to market survey and by establishing a management mechanism and controlling their service offer system. This paves the way for innovation and distinction among competitors. It will then be an issue of proactive service offer. 
It is also worth highlighting services around a product, the commitment in favour of customer service can only increase performance in the long term (Tzokas et al., 2000). Consequently, manufacturers have to enhance services that are destined to clients to achieve a better performance at the long run and create a higher value to clients.

Customised offers can largely enhance customer satisfaction. Consequently, marketing managers have to elaborate a precise approach, decide on a list of offered services and decide on their method and quality standards to finally decide on the price. This will allow it to efficiently control and manage its service activities.

Thanks to extra funds and some competence in such activities, the firm can guarantee a reliable service system. Limited resources or lack of experience should not discourage the managers from accentuating the offered service volume. Industrial firm has to take into account new laws for competitive games on the market. It has to rely on consolidating the relationship with its clients through services that create value for both the customers and the firm itself. Thus appears the importance of internal communication. Marketing managers have to try to 'sell this service project' internally before thinking to adopt a service-oriented marketing strategy. The aim is to work on involving the whole firm. In this line of thought, services will intervene in all the value chain which will enhance the success of service orientation. The favourable attitude and the motivation to offer services are not enough.

Industrial firms must equally take into account services' specificities for a better management of products/services. In fact, the intangible and heterogeneous aspect of services makes risk perception and the degree of uncertainty among clients higher than in a purchasing situation of a simple product. The challenge is to help the final client better assess this industrial 'paradoxical' offer. Offering different services according to customer type requires a good understanding of the needs of the target market. This efficient management reflecting the firm's market orientation will ensure the development of a reliable set of services in the long term. Managers have to really centre their efforts on the most important clients. This very tight vision can actually prevent the firm from keeping up with new market trends (Bonner and Walker, 2004; Slater and Narver, 1998; Tripsas, 1997). To have a very tight vision while privileging only clients cannot necessarily lead to a long-term performance. Nonetheless, if the firm becomes highly involved in offering services, a significant risk appears. The challenge lies in avoiding the creation of new competitors, mainly service-providing firms. Usually, outsourcing some activities can be a pertinent solution.

The main limit of this present paper is to use only a qualitative research to determine the antecedents of service orientation. We then suggest to realise in the next stage a quantitative research to test more precisely the effects of these factors on service orientation.

In addition, we can examine the relationship between service orientation and performance of industrial firm.

Finally, for future studies, we propose to realise a complementary longitudinal study to understand the dynamics of the relation orientation service and performance.

\section{References}

Agency for the Promotion of Industry and Innovation (API) (2012) Stratégie industrielle $\grave{a}$ horizon (2016), http://www.tunisieindustrie.nat.tn/fr/download/CEPI/Synthese.pdf (Accessed 12 February, 2012). 
Almeida, L.F. and Miguel, P.A.C. (2009) 'Product related service and the product development process: a preliminary analysis and research project outline', POMS 20th Annual Conference, No. 011-713, 1-4 May, Orlando, Florida, USA.

Alrubaiee, L. (2013) 'An investigation on the relationship between new service development, market orientation and marketing performance', European Journal of Business and Management, Vol. 5, No. 5, pp.1-26.

Antioco, M., Moenaert, R.K.M., Lindgreen, A. and Wetzels, M.G.M. (2008) 'Organizational antecedents to and consequences of service business orientation in manufacturing companies', Journal of the Academy Marketing Science, Vol. 36, No. 3, pp.337-358.

Asikhia, O. (2010) 'Customer orientation and firm performance among Nigerian small and medium scale businesses', International Journal of Marketing Studies, Vol. 2, No. 1, pp.197-212.

Baines, T.S., Lightfoot, H., Benedettini, O. and Kay, J.M. (2009) 'The servitization of manufacturing: a review of literature and reflection on future challenges', Journal of Manufacturing Technology Management, Vol. 20, No. 5, pp.574-567.

Balgin, G. and Malleret, V. (2004) Le développement d'offre de services dans les PMI, Working paper, HEC Group, No. 800/2004.

Banks, C.H. (2006) 'Diffusion of innovation: communicating to improve training and employee development', Int. J. of Strategic Change Management, Vol. 1, Nos. 1-2, pp.143-154.

Bonner, J.M. and Walker, O.C. (2004) 'Selecting influential business-to-business customers in new product development: relational embeddedness and knowledge heterogeneity considerations', Journal of Product Innovation Management, Vol. 21, No. 3, pp.155-169.

Bowen, D.E., Siehl, C. and Schneider, B. (1989) 'A framework for analyzing customer service orientation in manufacturing', Academy of Management Review, Vol. 14, No. 1, pp.75-95.

Brady, M.K. and Cronin, J. (2001) 'Customer orientation: effects on customer service perceptions and outcome behaviors', Journal of Service Research, Vol. 3, No. 3, pp.241-251.

Cran, D.J. (1994) 'Towards validation of the service orientation construct', The Service Industries Journal, Vol. 14, No. 1, pp.34-44.

Day, G.S. (1994) 'The capabilities of market-driven organizations', Journal of Marketing, Vol. 58, No. 4, pp.37-52.

Denis, J.E., Graber, S. and Czellar, S. (2000) Orientation marché et performance: intégration des évidences empiriques, Working paper, HEC, University of Geneva.

Driver, C. and Johnston, R. (2001) 'Understanding service customers: the value of hard and soft attributes', Journal of Service Research, Vol. 4, No. 2, pp.27-36.

Eiglier, P. and Langeard, E. (1987) Servuction: Le marketing des services, Collection Stratégie et management, McGraw-Hill, Paris.

Furrer, O. (1997) Orientation client et service autour des produits informatiques, $\mathrm{PhD}$, Faculté des sciences économiques, University of Neuchatel, Switzerland.

Furrer, O. (1998) 'Services autour des produits : L'offre des entreprises informatiques', Revue Française de Marketing, Vol. 166, No. 1, pp.96-105.

Gadolin, C. (2014) 'Internal communication for change: a complex challenge', Int. J. of Strategic Change Management, Vol. 5, No. 3, pp.175-188.

Gauthy-Sinéchal, M. and Vandercammen, M. (2005) Etude de marché: methods et outils, 2nd ed., De Boeck, Bruxelles, pp.136-137.

Gebauer, H. (2008) 'Identifying service strategies in product manufacturing companies by exploring environment-strategy configurations', Industrial Marketing Management, Vol. 37, No. 3, pp.278-291.

Gebauer, H. and Fleisch, E. (2007) 'An investigation of the relationship between behavioral processes, motivation, investments in the service business and service revenue', Industrial Marketing Management, Vol. 36, No. 3, pp.337-348.

Gebauer, H., Fleish, E. and Friedli, T. (2005) 'Overcoming the service paradox in manufacturing companies’, European Management Journal, Vol. 23, No. 1, pp.14-26. 
Gebauer, H., Gustafsson, A. and Witell, L. (2011) 'Competitive advantage through service differentiation by manufacturing companies', Journal of Business Research, Vol. 64, No. 12, pp.1270-1280.

Gotteland, D., Haon, C. and Gauthier, C. (2007) 'L'orientation marché : Synthèse et nouvelles directions théoriques', Recherche et Applications en Marketing, Vol. 22, No. 1, pp.45-59.

Grönroos, C. and Ravald, A. (2011) 'Service as business logic: implications for value creation and marketing', Journal of Service Management, Vol. 22, No. 1, pp.5-22.

Hogan, J., Hogan, R. and Busch, C.M. (1984) 'How to measure service orientation?', Journal of Applied Psychology, Vol. 69, No. 1, pp.167-173.

Homburg, C., Hoyer, W.D. and Fassnacht, M. (2002) 'Service orientation of retailer's business strategy: Dimensions, Antecedents, and performance outcomes', Journal of Marketing, Vol. 66, No. 4, pp.86-101.

Jaworski, B.J. and Kohli, A.K. (1993) 'Market orientation: antecedents and consequences', Journal of Marketing, Vol. 57, No. 3, pp.53-71.

Jaworski, B.J. and Kohli, A.K. (1996) 'Market orientation: review, refinement, and roadmap', Journal of Market Focused Management, Vol. 1, No. 2, pp.119-135.

Ketchen, D.J., Hult, G.T.M. and Slater, S.F. (2007) 'Toward greater understanding of market orientation and the resource-based review', Strategic Management Journal, Vol. 28, No. 9, pp.961-964.

Khalique, M., Shaari, J.A.N., Hassan, A. and Samad, N. (2013) 'Impact of intellectual capital on the organizational performance of Islamic banking sector in Malaysia', Asian Journal of Finance \& Accounting, Vol. 5, No. 2, pp.75-83.

Kirca, A.H., Jayachandran, S. and Bearden, W.O. (2005) 'Market orientation: a meta-analytic review and assessment of its antecedents and impact on performance', Journal of Marketing, Vol. 69, No. 2, pp.24-41.

Kotler, P. (1997) Marketing Management: Analysis, Planning, Implantation and Control, 9th ed., Prentice Hall, 832 p.

Kumar, R. and Markeset, T. (2007) 'Development of performance-based service strategies for the oil and gas industry: a case study', Journal of Business \& Industrial Marketing, Vol. 22, No. 4, pp.272-280.

Lay, G., Copani, G., Jäger, A. and Biege, S. (2010) 'The relevance of service in European manufacturing industries', Journal of Service Management, Vol. 21, No. 5, pp.715-726.

Lee, Y.I. (2004) 'Customer service and organizational learning in the context of strategic marketing', Marketing Intelligence \& Planning, Vol. 22, Nos. 6-7, pp.652-662.

Lovelock, C., Wirtz, J., Lapert, D. and Munos, A. (2008) Marketing des services, 6th ed., Pearson Education, France, pp.7-11.

Lytle, R.S., Hom, P.W. and Mokwa, M.P. (1998) 'SERV*OR: a managerial measure of organizational service orientation', Journal of Retailing, Vol. 74, No. 4, p. 447-454.

Malleret, V. (2005) 'La rentabilité du service dans les entreprises industrielles', 26th Congress of $A F C$, Lille, France, pp.1-26.

Malleret, V. (2006) 'La création de la valeur par les services: une étude empirique dans des PMI', Finance Contrôle Stratégie, Vol. 9, No. 3, pp.67-104.

Mathieu, V. (2001a) 'Product services: from a service supporting the product to a service supporting the client', Journal of Business and industrial Marketing, Vol. 16, No. 1, pp.39-58.

Mathieu, V. (2001b) 'Service strategies within the manufacturing sector: benefits, costs and partnership', International Journal of Service Industry Management, Vol. 12, No. 5, pp.451-475.

Mathieu, V. (2004) 'Les stratégies orientées services dans l'industrie', Décisions Marketing, Vol. 33, No. 1, pp.19-29. 
Millson, M.R. and Wilemon, D. (2002) 'The impact of organizational integration and product development proficiency on market success', Industrial Marketing Management, Vol. 31, No. 1, pp.1-23.

Mosadeghrad, A.M. and Ansarian, M. (2014) 'Why do organisational change programmes fail?', Int. J. of Strategic Change Management, Vol. 5, No. 3, pp.189-218.

Narver, J.C. and Slater, S.F. (1990) 'The effect of a market orientation on business profitability', Journal of Marketing, Vol. 54, No. 4, pp.20-35.

Olivia, R. and Kallenberg, R. (2003) 'Managing the transition from products to services?', International Journal of Service Industry Management, Vol. 14, No. 2, pp.160-172.

Ordonez De Pablos, P. (2004) 'The importance of relational capital in service industry: the case of the Spanish banking sector', International Journal of Learning and Intellectual Capital, Vol. 1, No. 4, pp.431-459.

Pellemans, P. (1999) La recherché qualitative en marketing, Perspective psychoscopique, Department of Boeck University of Paris, pp.86-175.

Pettus, M.L., Kor, Y.Y. and Mahoney, J.T. (2009) 'A theory of change in turbulent environments: the sequencing of dynamic capabilities following industry deregulation', Int. J. of Strategic Change Management, Vol. 1, No. 3, pp.186-211.

Philippe, J. and Leo, P.Y. (1996) Les couples produits-services, voie de développement pour les PME exportatrices, Working paper, No. 190, Centre d'économie régionale, Université d'AixMarseille III.

Pinet, J. and Coupet, A. (2009) 'Créer une culture de service, une question de leadership', Gestion, Vol. 33, No. 4, pp.48-57.

Reffait, P. (1993) 'Marché Unique: nécessité et conditions d'un marketing produit-service fort pour les PMI', Proceedings of the «PME-PMI, développement international», June, Aix en Provence, CER, France.

Ren, G. and Gregory, M. (2007) 'Servitization in manufacturing companies: a conceptualization, critical review, and research agenda', 16th Annual Frontiers in Service Conference, 4-7 October, San Francisco, California, USA.

Rock, G. and Ledoux, M.J. (2006) Le service à la clientèle, Éditions du Renouveau Pédagogique, France, $346 \mathrm{p}$.

Salonen, A. (2011) 'Service transition strategies of industrial manufacturers', Industrial Marketing Management, Vol. 40, No. 5, pp.683-690.

Slater, S.F. and Narver, J.C. (1998) 'Customer-led and market-oriented: let's not confuse the two', Strategic Management Journal, Vol. 19, No. 10, pp.1001-1006.

Slepniov, D., Waehrens, B. and Johansen, J. (2010) 'Servitization as a strategy for survival: an investigation of the process in Danish manufacturing firms', Paper for the 15th Cambridge International Manufacturing Symposium, 23-24 September, Cambridge, UK, pp.1-12.

Solnet, D. and Kandampully, J. (2005) 'Service orientation as a strategic initiative: a conceptual model with exemplars', Alliance Journal of Business Research, Vol. 1, No. 2, pp.1-20.

Solnet, D. and Kandampully, J. (2006) 'Antecedents and dimensions of service orientation: a conceptual framework', CAUTHE 2006 Conference: To the City and Beyond, 6-9 February, Melbourne, pp.320-335.

Tan, A.R., Matzen, D., McAloone, T.C. and Evans, S. (2010) 'Strategies for designing and developing services for manufacturing firms', Journal of Manufacturing Science and Technology, Vol. 3, No. 2, p.46-59.

Tournois, L. and Montbello, M. (2001) La création de la valeur pour le client, source de la performance concurrentielle des entreprises, Working Paper No. 623, IAE, University of Aix-Marseille III.

Tripsas, M. (1997) 'Unravelling the process of creative destruction: complementary assets and incumbent survival in the typesetter industry', Strategic Management Journal, Vol. 18, Summer Special Issue, pp.119-142. 
Tzokas, N., Donaldson, B. and Sade, A.B. (2000) 'L'impératif du service client dans l'industrie', Recherche et Applications en Marketing, Vol. 15, No. 1, pp.21-38.

Vandenbosch, M.B. and Weinberg, C.B. (1994) 'Setting the strategic direction in a product-service firm', Journal of Business Research, Vol. 31, Nos. 2-3, pp.117-132.

Vandermerwe, S. and Rada, J. (1988) 'Servitization of business: adding value by adding services', European Management Journal, Vol. 6, No. 4, pp.314-324.

Vargo, S.L. and Lusch, R.F. (2004)'Evolving to a new dominant logic for marketing', Journal of Marketing, Vol. 68, No. 1, pp.1-17.

Vargo, S.L. and Lusch, R.F. (2008) 'From goods to service(s): divergences and convergences of logics', Industrial Marketing Management, Vol. 37, No. 3, pp.254-259.

Venkatesh, V. and Davis, F.D. (2000) 'A theoretical extension of the technology acceptance model: four longitudinal field studies’, Management Science, Vol. 46, No. 2, pp.186-204.

Vroom, V. (1964) Work and Motivation, John Wiley, New York.

Wagner, W.B. and La Garce, R. (1981) 'Customer service as a marketing strategy', Industrial Marketing Management, Vol. 10, No. 1, pp.31-41.

Xu, X.G., Han Wen, M. and Ye Tao, F. (2011) 'Flexibility of service-oriented manufacturing: a literature review', African Journal of Business Management, Vol. 5, No. 35, pp.13534-13540. 